\title{
MODELLING OF HEAT GENERATION AND TRANSFER IN METAL CUTTING: A SHORT REVIEW
}

\begin{abstract}
This paper overviews thermal fundamentals in metal cutting process for the determination of the amount of heat in the cutting zone which represents the interfaces between the cutting tool, the chip and the workpiece materials. Different measuring and predicting techniques of the tool-chip contact temperature and corresponding heat flux based on the estimated heat partition are outlined. The main focus was on the differently coated cutting tools and their role in controlling thermal behaviour of the cutting process. The computed algorithms for analytical and numerical methods as well as their main advantages and disadvantages, and practical applications in machining are overviewed. A number of practical solutions obtained in the Department of Manufacturing Engineering, TU of Opole are presented.
\end{abstract}

\section{INTRODUCTION}

The experimental and analytically and numerically-based investigations of the performance of the cutting process are predominantly focused on two fundamental physical phenomena involving intensive plastic deformation of the removed material and associated friction at the contact surfaces of the cutting tool (correspondingly primary - PDZ (1), secondary - SDZ (2) and tertiary - TDZ (3) deformation subzones in Fig. 1a. This is due to the fact that both these phenomena are not only responsible for the mechanical loads and power consumption but cause that generated mechanical energy is converted into heat with an overall efficiency of about $99.5 \%[1,2]$.

It should be noted in Fig. 1b that the modelling of the coupled thermo-mechanical material behaviour is a very difficult engineering task resulting from many physical and technical restrictions in its characterization with an acceptable accuracy.

In particular, extremely high strains and strain rates of about $\varepsilon=8$ and $\dot{\varepsilon}=10^{5} \mathrm{~s}^{-1}$ along with the working temperatures exceed $1000^{\circ} \mathrm{C}$ and temperature gradients of $2 \times 10^{6} \mathrm{~K} / \mathrm{s}$ are documented in the cutting zone $[3,4]$. As a consequence, friction along the tool-chip interface occurs at very high contact pressure, for instance at the level of 3.5 GPa reported in [5], and high temperature. Some experimental techniques especially suited for metal cutting process,

\footnotetext{
${ }^{1}$ Opole University of Technology, Opole, Poland

*E-mail: w.grzesik@po.edu.pl

https://doi.org/10.36897/jme/117814
} 
such as Laser Flash Method (LFM) for identification of thermal properties of cutting tool coatings at high temperatures or Split Hopkinson's Pressure Bar (SHPB) and Taylor's impact test for identification of the equivalent strain rate at ultra-high strain rates are overviewed in $[1,4]$.

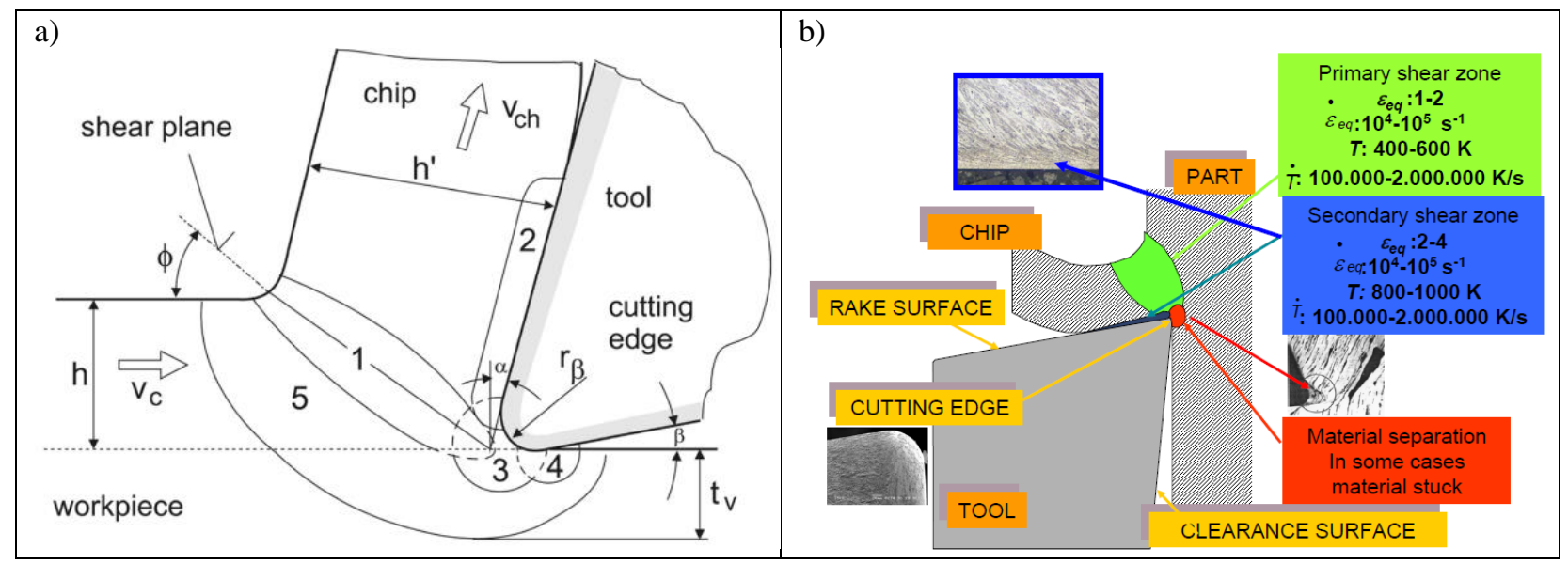

Fig. 1. Characteristic zones in the metal cutting process (a) and typical thermo-mechanical conditions occurred $[1,3]$

The general classification of predictive models utilized in metal cutting investigations are shown in Fig. 2. The physics-based analytical models can predict such process characteristics as forces, friction, stresses, strain rates and temperatures but due to the complexity of real processes they are not suitable for predicting all industry relevant outcomes. On the other hand, they provide useful inputs for optimising numerical models. The numerical models, mainly based on FE methods, can offer quite realistic prediction of industry relevant outputs. The hybrid analytical/numerical approach seems to be rational solution when process variables are, for instance, temperature-dependent ones or they depend on the assumed boundary conditions, including friction. Hybrid modelling can combine some of the analytical, numerical or Artificial Intelligence (AI)-based methods including neural networks, genetic algorithms, swarm intelligence, and other learning methods in order to expand the capabilities of empirical models [3]. In this survey, physics-based analytical, numerical and hybrid analytical-numerical modelling methods are mostly considered.

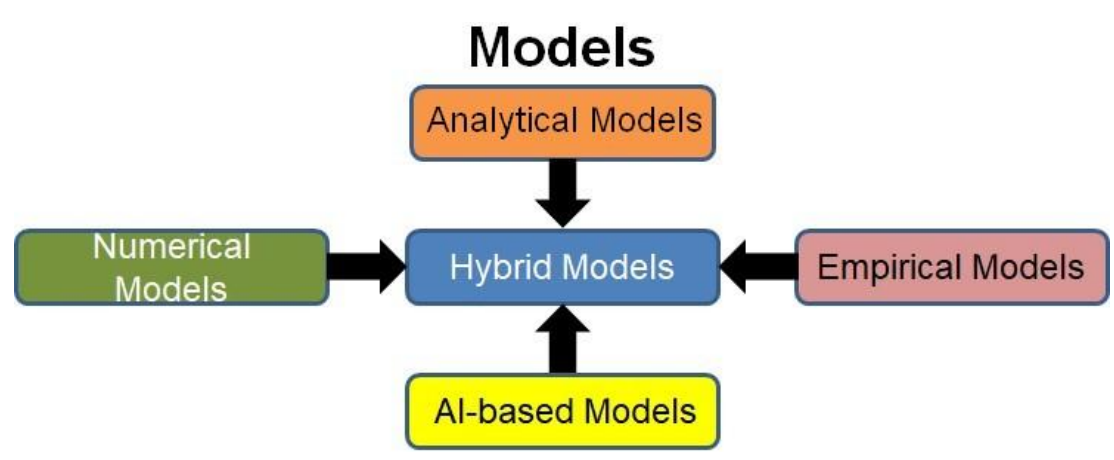

Fig. 2. General classification of models used in metal cutting investigations [3] 


\section{GENERATION OF INPUT DATA FOR THERMAL MODELLING}

Overall scheme of the measurements and subsequent computations performed in both in-process and post-process modes is presented in Fig. 3. In general, several classical measurement techniques such as piezoelectric dynamometry, thermocouple method or IR thermography, digital image processing are applied in order to measure or determine the cutting forces, the thermal EMF signals, thermographs, the tool-chip contact area and its length. The experimentally obtained process characteristics are used to determine main process quantities which are utilized as the input data for thermo-mechanical modelling of the cutting process or verification of the predicted data. In addition, closed (adopted) tribometers are frequently used to test deposited coatings with respect to the sliding friction [4-7]. This method is effectively used to determine the friction coefficient values for variable load and sliding velocity characteristic for the SDZ.

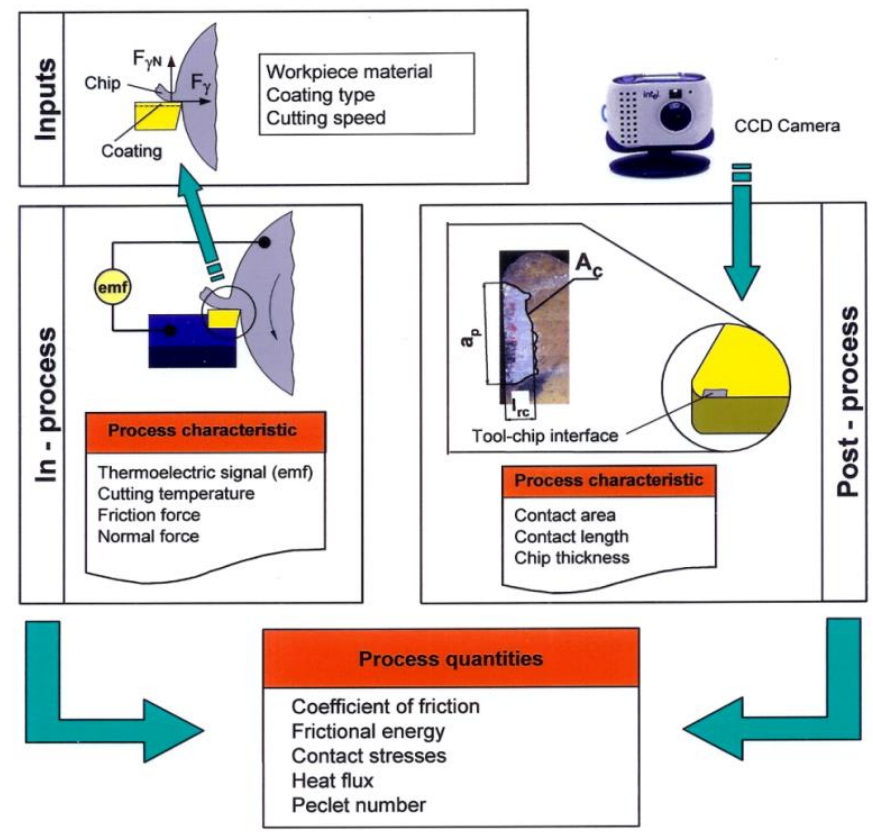

Fig. 3. Schematic illustration of measuring platform for metal cutting applications [8]

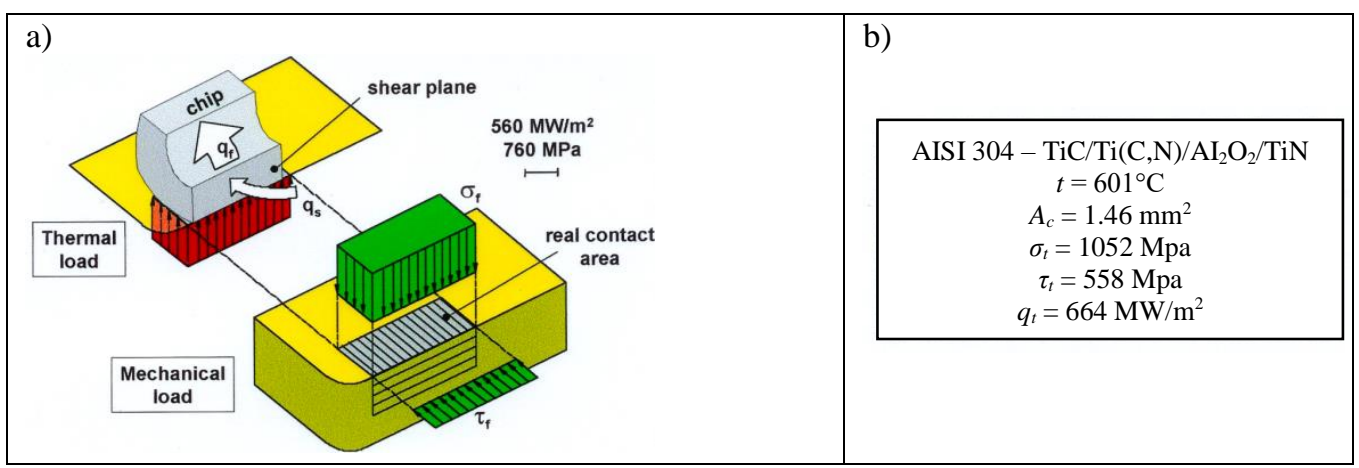

Fig. 4. Distribution of mechanical and thermal loads (a), determined from measured forces and contact areas and their values in machining of AISI 304 steel using multilayer TiC/Ti(C,N)/ $\mathrm{Al}_{2} \mathrm{O}_{3} / \mathrm{TiN}$ coated carbide tool (b) [9] 
Exemplarily, Fig. 4 shows the distribution of the normal $\sigma_{f}$ and shear $\tau_{f}$ stresses acting on the tool-chip contact area $A_{c}$ which was determined by means of planimetry of the real contact area shown in Fig. 3. The normal and friction forces (see also Fig. 3) are computed by resolving the components of the resultant cutting force on the shear plane and the rake face [1]. Consequently, heat fluxes in the PDZ and SDZ were computed as the ratios of shear and friction energies to the shear plane and the tool-chip contact areas respectively.

\section{ANALYTICAL MODELLING OF HEAT FLOW IN THE CUTTING ZONE}

Figure 5 shows the flow chart developed for analytical computation of the average and maximum temperatures at the tool-chip interface based on the determination of heat partition coefficient $\left(R=R_{\mathrm{ch}}\right.$ ), which defines the percentage of heat flowing into the chip. The fraction $(1-R)$ quantifies the percentage of the dissipated energy going to the tool. This methodology is described in $[1,10]$.

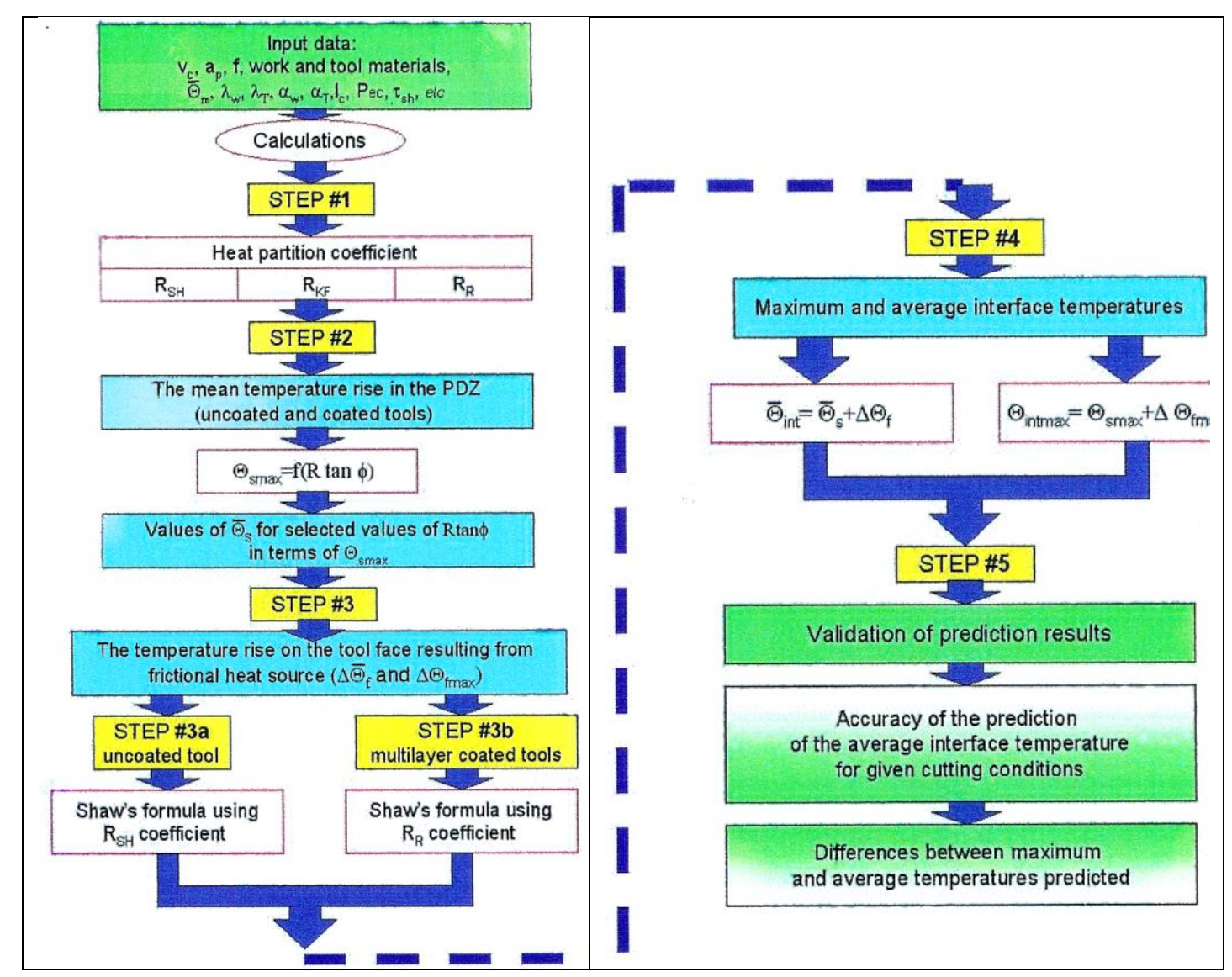

Fig. 5. Flow chart for analytical prediction of the average and maximum values of the temperature on the tool-chip contact interface [10]

$$
R_{R_{1}}=\frac{1}{1+\left[\left(3 \lambda_{T} / 2 \lambda_{W}\right) \sqrt{P e_{T} F o_{W}}\right]}
$$


where:

$$
P e_{T}=\frac{v_{c h} l_{c}}{\alpha_{T}} \quad \text { and } \quad F o_{W}=\frac{\alpha_{W} \tau_{c}}{l_{c}^{2}}=\frac{\alpha_{W}}{l_{c} v_{c h}}
$$

where: $v_{c h}$ is the chip sliding speed, $l_{c h}$ is the tool-chip contact length and $\tau$ is the contact duration, $\lambda_{T}$ and $\lambda_{W}$ denote thermal conductivity of the tool $T$ and the workpiece (chip) $W$ materials, $\alpha_{T}$ and $\alpha_{W}$ are corresponding symbols of thermal diffusivities.

$$
\begin{aligned}
& R_{\mathrm{KF}}=\frac{1}{1+\sqrt{\left(c_{p} \rho \lambda\right)_{T} /\left(c_{p} \rho \lambda\right)_{W}}} \\
& R_{\mathrm{R}_{2}}=\frac{1}{1+\left[\left(3 \lambda_{T} / 2 \lambda_{W}\right) \sqrt{\alpha_{W} / \alpha_{T}}\right]}
\end{aligned}
$$

where $\left(\lambda \rho c_{p}\right)$ is the triple product of the thermal conductivity, the density and the specific heat.

In this computation algorithm, two different formulae for calculation of the $R$ coefficient were tested, i.e. $R_{\mathrm{KF}}$ and $R_{\mathrm{R}}$ proposed by Kato and Fujii (1d) and Reznikov (1a and 1c) $[1,11,12]$. However, the third one (Eqns. 1a and 1c), which considers two dimensionless thermal numbers, namely the Peclet $(\mathrm{Pe})$ and Fourier $(\mathrm{Fo})$ numbers defined by Eqn. $1 \mathrm{~b}$ was selected for further analysis. The results obtained for the plain heat source model are shown in Fig. 6a. Figure 6a reveals that for higher values of the product of $\mathrm{Pe}_{T}$ and $\mathrm{FoW}_{\mathrm{W}}$ a great amount of the generated heat flows into the chip, which is practically observed in High Speed Machining (HSM). Opposite situation occurs in the machining of heat resistant alloys with low thermal conductivity.

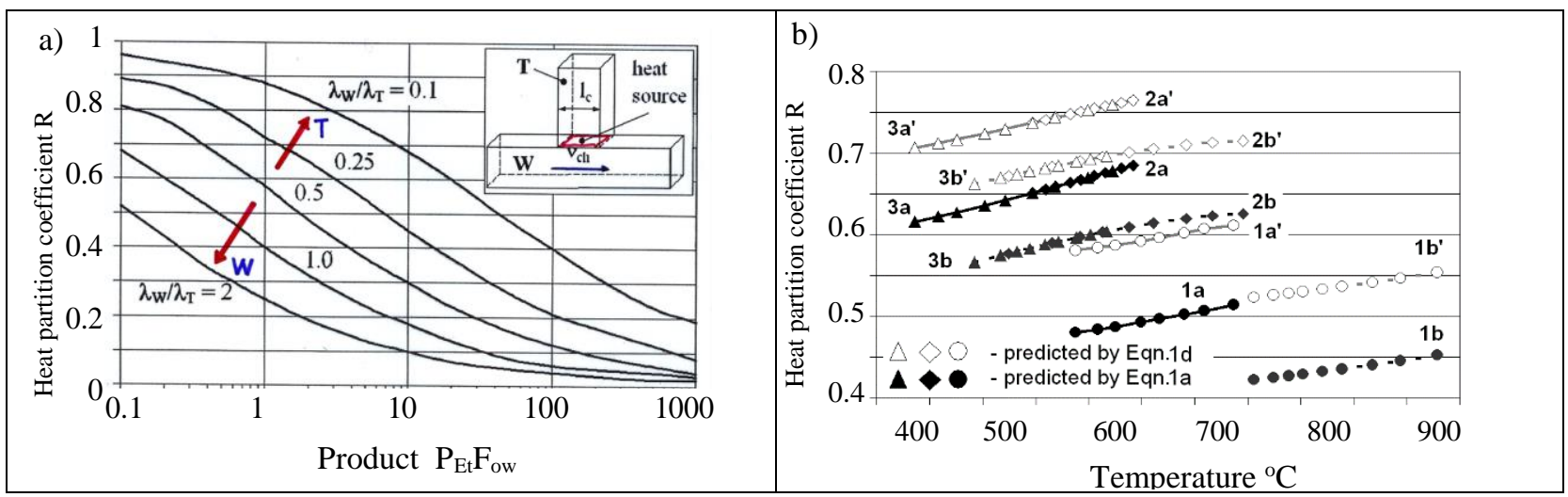

Fig. 6. Plot showing the dependence of heat partition at the tool-chip contact on the product of Peclet $\left(\mathrm{Pe}_{\mathrm{T}}\right)$ and Fourier (Fow) thermal numbers (a) and heat partition vs temperature (b): 1 - uncoated carbide grade $\mathrm{HW} 20,2-\mathrm{TiC}_{\mathrm{Al}} \mathrm{O}_{3} / \mathrm{TiN}$, 3 - TiC/Ti(C,N)/ $\mathrm{Al}_{2} \mathrm{O}_{3} / \mathrm{TiN}$; a) - AISI 1045 carbon steel, b) - AISI 304 stainless steel [11]

Figure $6 \mathrm{~b}$ highlights the evolution of heat partition resulting from temperature rise for AISI 1045 carbon and AISI 304 stainless steels and comparatively for uncoated and coated cutting tools. It is evident that the heat partition coefficient increases up to 0.75 when cutting temperature rises and this effect is more pronounced for multi-layered coatings. Moreover, predictions based on Eqn. (1c) provide lower values of $R_{c h}$ coefficient than those based on Eqn. (1d) without consideration of the contact time (for instance courses denoted by $a$ and $a^{\prime}$ ). In general, the $R_{c h}\left(R_{R}\right)$ values for uncoated tools are calculated in the range of 0.4-0.5. 


\section{NUMERICAL MODELLING OF HEAT DISTRIBUTION IN THE CUTTING ZONE}

In this section the FEM and FDM simulation techniques are shortly overviewed along with some representative case studies showing their applicability to various metal cutting problems including thermal behaviour of the material in the PDZ and SDZ. The FEM techniques, such as Lagrangian, Eulerian and ALE (Arbitrary Lagrangian-Eulerian) are characterized in numerous literature issues from metal cutting modelling including [1, 3, 4]. Several commercial FEM packages, such as DEFORM, ABAQUS, Advant Edge are used. The simulation success depends on reliable input data, in particular, on the material constitutive model which characterizes material behavior under high strain, high strain rates and high temperature corresponding to the thermo-mechanical conditions that proximately exist in the cutting zones. The most popular is the Johnson-Cook (J-C) model but also the power law model and Oxley's model provide acceptable results [1, 3]. Other models incorporate such effects as material failure, material microstructure or material hardness. The J-C constitutive model, which consists of elastic-plastic, viscosity and thermal softening terms (Fig. 7a) is presented in the following form $[1,3]$ :

$$
\sigma_{\mathrm{eq}}=\left(A+B \varepsilon_{p}{ }^{n}\right)\left(1+C \ln \left(\frac{\dot{\varepsilon}_{p}}{\dot{\varepsilon}_{p}^{0}}\right)\right)\left(1-\left(\frac{T-T_{r}}{T_{m}-T_{r}}\right)^{m}\right)
$$

where: $\varepsilon_{p}-$ the equivalent strain, $\dot{\varepsilon}_{p}-$ the equivalent strain rate, $\dot{\varepsilon}_{p}^{0}$ - the strain rate equal to $1.0 \mathrm{~s}^{-1}, T$ - the absolute temperature, $T_{r}$ - the room (ambient) temperature, $T_{m}$ - the melting temperature of a specific metal

The application of raw literature data is debatable because high errors can be generated in relation to experimentally obtained data. In such cases, the need to determine more accurate material constitutive equation occurs. Fig. 7a shows the methodology and appropriate testing apparatuses for determination of material constants in the $\mathrm{J}-\mathrm{C}$ constitutive model for Inconel 718 alloy and the results obtained are illustrated in Fig. 7b.

A special procedure for the prediction of parameters of the Johnson-Cook constitutive material models is proposed based on the experimental data and specially developed MATLAB scripts which allow advanced modelling of complex 3D response surfaces shown in Fig. 7b. Experimental investigations concern two various strain rates of $10^{-3}$ and $10^{1} 1 / \mathrm{s}$ and the testing temperature ranging from the ambient up to $700^{\circ} \mathrm{C}$. As can be seen in Fig. $7 \mathrm{~b}$ substantial differences can appear in predicting the flow stress values at high temperatures.

The main problem which appears is the selection of five material constants $(A, B, C$, $n, m)$. Their values are typically obtained through the testing of material samples in experimental high-speed equipment such as Taylor's impact tests or Hopkinson's compression and shear devices (they were mentioned in Introduction). Another important problem is identification of friction law parameters.

Figure 8a presents an example of discretization of the cutting zone, available in popular commercial FEM packages, AdvantEdge. As can be seen in Fig. 8a the mesh is highly refined in the primary and secondary shear zones in order to expose the cutting edge radius and a thin coating (see a fragment of the coated cutting edge). The finite difference method (FDM) can be used to solve the heat transfer problem in the cutting zone and generate the temperature fields in the chip and the adjacent area within the tool. It is assumed that for the idealized 
model of the cutting process the heat sources resulting from shearing at the shear plane and friction at the tool-chip interface are represented by one plane, uniformly distributed heat source at the tool-chip interface.

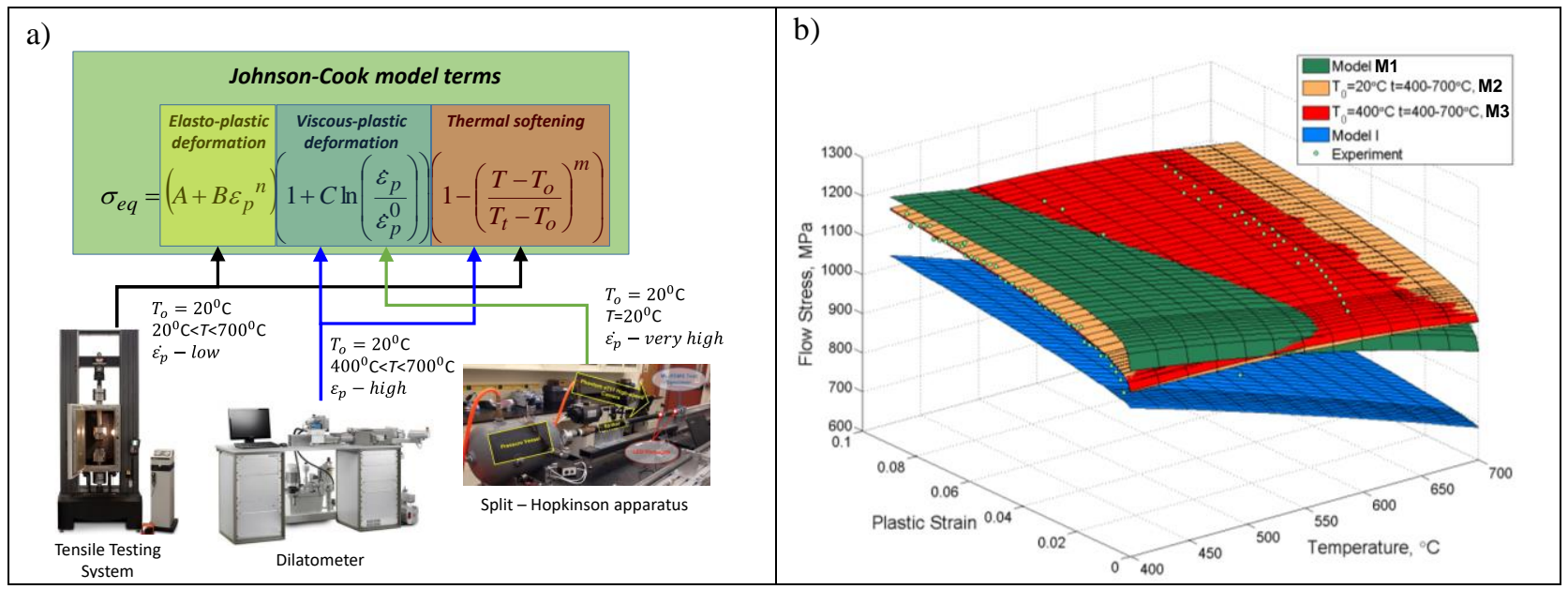

Fig. 7. Determination of material constants in the J-C model (a) and comparison of three versions of determined models with experimental data for Inconel 718 alloy [12] (b). Symbols: M1 - model for temperature range of $20^{\circ} \mathrm{C}-700^{\circ} \mathrm{C}$, $\mathrm{M} 2$ - model for temperature range of $400^{\circ} \mathrm{C}-700^{\circ} \mathrm{C}$ and $T_{o}=20^{\circ} \mathrm{C}, \mathrm{M} 3$ - model for temperature range of $20^{\circ} \mathrm{C}-700^{\circ} \mathrm{C}$ and $T_{o}=400^{\circ} \mathrm{C}$

The FDM model shown in Fig. $8 \mathrm{~b}$ is built as a set of cells including adequate formulae and values, which finally represents both geometrical and physical features of the modelled process. Formulae are introduced according to the explicit method of the difference procedure. Moreover, a steady two-dimensional heat flow problem is assumed.

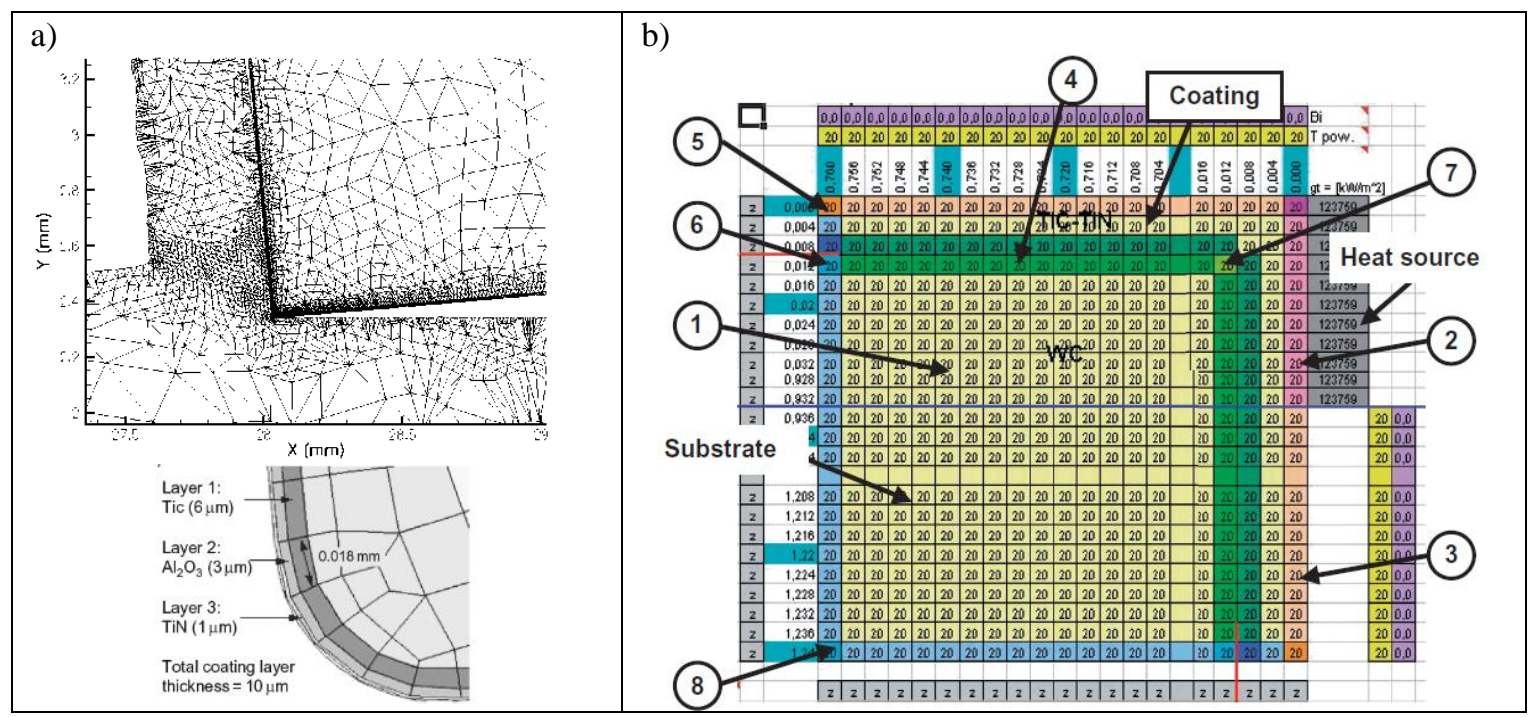

Fig. 8. Example of finite element mesh used in modelling the cutting zone, generated in AdvantEdge FEM package (a) and FDM mesh (b) using coated cutting tools [1, 13, 14]. Numbers in Fig.8b: 1 - formulae inside the calculation field; 2 - Neuman's condition for the tool-chip interface; 3 - Fourier's condition for air cooling; 4 - condition of fourth type with ideal thermal contact; 5 - Fourier/Neuman's condition for the corner; 6 - Neuman's/fourth type condition for the corner; 7 - mixed fourth/fifth type condition for the internal corner; 8 - mixed Neuman/Neuman's condition 
The obtained results are presented in Figs. 9a and 9b for FEM-based and FDM-based predictions, respectively.
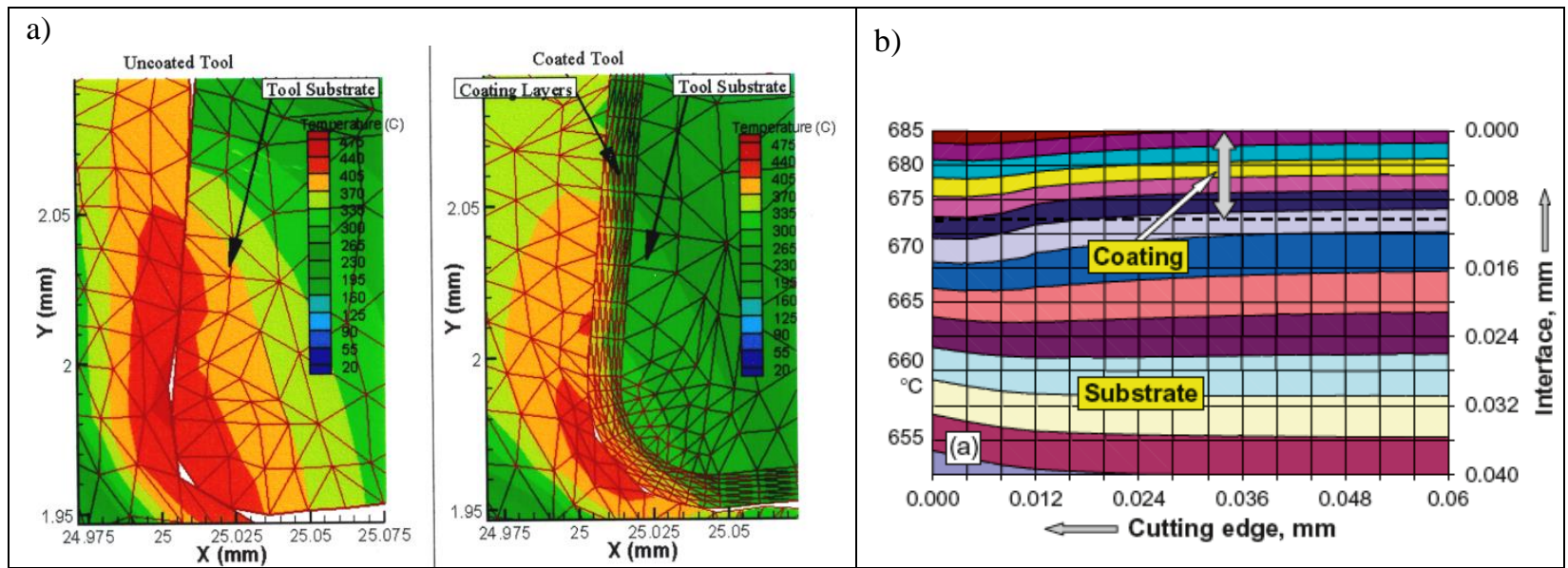

Fig. 9. Simulated distributions of temperature in the coated tools using FEM (a) and FDM (b) for TiC/Al ${ }_{2} \mathrm{O}_{3} / \mathrm{TiN}^{-\mathrm{AISI}}$ 1045 pair and cutting speed of $145 \mathrm{~m} / \mathrm{min}[1,14,15]$

Another important comparison related to the contact temperature evolution up to the steady-state level is presented in Figs. 10a and b. It was established based on these records that the time required to reach a constant temperature is $0.35-0.60 \mathrm{~ms}$ depending on the cutting tool material used. The values of the average contact temperature estimated are about $680^{\circ} \mathrm{C}$ for uncoated and $650^{\circ} \mathrm{C}$ for tools coated with a $10 \mu \mathrm{m}$ thick layer, respectively. In this comparison the Coulomb friction law $(\mu=0.5)$ was assumed.

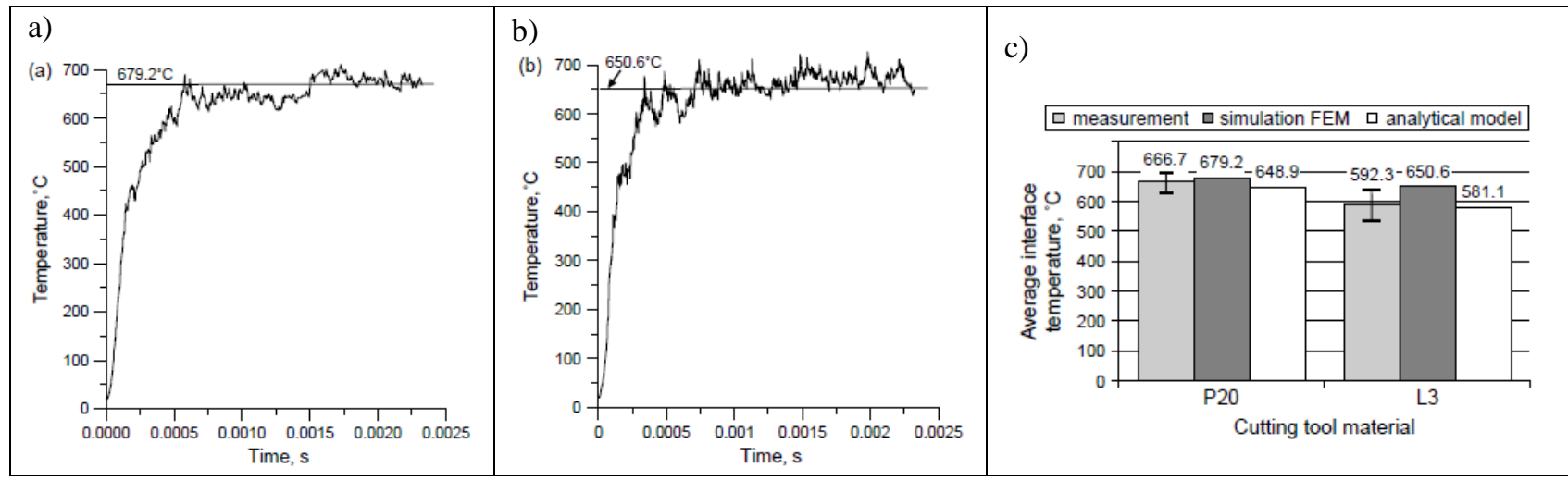

Fig. 10. Traces of temperature evolution vs. simulation time for uncoated HW20 (P20) (a) and TiC/Al ${ }_{2} \mathrm{O}_{3} / \mathrm{TiN}_{\text {(L3) }}$ coated tools (b) and comparison of average temperatures (c) using analytical and FEM models with equivalent thermal properties. Workpiece material - AISI 1045 steel, cutting speed of $103.6 \mathrm{~m} / \mathrm{min}[16,17]$

\section{HYBRID MODELLING OF HEAT DISTRIBUTION IN THE CUTTING ZONE}

Composite layer-based modelling concept assumes the multilayer coating as a stack of individual layers with defined thickness, density and thermal properties (conductivity and diffusivity) which can be replaced by a homogenous single layer with equivalent thermal 
properties [16-19]. The equivalent thermal conductivity $\lambda_{\text {eq }}$ and thermal diffusivity $\alpha_{\text {eq }}$ of a composite monolayer coating can be determined using the following formulae:

$$
\frac{\sum_{1}^{t} x_{i}}{\lambda_{\mathrm{eq}}}=\frac{x_{1}}{\lambda_{1}}+\frac{x_{2}}{\lambda_{2}}+\ldots \ldots+\frac{x_{t}}{\lambda_{t}}
$$

where $x_{i}$ and $\lambda_{i}$ are the thickness and the thermal conductivity of $i$-layer of the deposited multilayer coating.

$$
C_{\mathrm{eq}}=\frac{\sum_{1}^{t}\left(x_{i} C_{i}\right)}{\sum_{1}^{t} x_{i}} \text { and } \alpha_{\mathrm{eq}}=\frac{\lambda_{\mathrm{eq}}}{C_{\mathrm{eq}}}
$$

where $C_{i}=c_{p i} \times \rho, c_{p i}$ and $\rho_{i}$ denote the volumetric heat capacity, the specific heat and density of $i$-layer of the deposited multilayer coating respectively.

As a consequence, the equivalent thermal properties can be used in both analytical [18-20] and numerical [16,17] modelling. For instance Fig. 9c shows the comparison between the predictions based on analytical and numerical calculations using the equivalent thermal properties for a three layer coating. It is clear, that analytical prediction provides the average temperature value with the accuracy of about 3-5\%. However, the FEM-based simulation overestimated the measuring results obtained for coated tools due to inadequate friction estimation. This problem is discussed in Refs. [4, 7, 21, 22] but it is further an open question in metal cutting modelling.

\section{CONCLUSIONS}

In general, it is not possible to perfectly model metal cutting processes due to very complex mechanical, thermodynamical and tribological interactions existing in the cutting zone and especially in the secondary deformation zone (SDZ). For this purpose several modelling methods and appropriate experimental techniques to generate more accurate material constitutive models are developed and designed. In these case studies the 2D FEM modelling was applied but the most promising seems to be the 3D FEM approach which reproduces satisfactorily thermo-mechanical conditions produced in the secondary cutting zone. Moreover, apart from the cutting pressure also contact temperature and heat flux are controlled during simulations performed. In order to improve the prediction accuracy some analytical and hybrid solutions are necessary. However, the accuracy of the predictions depends strongly on the input data including thermo-physical properties and contact conditions of the tool-workpiece material coupled.

\section{REFERENCES}

[1] GRZESIK W., 2017, Advanced machining processes of metallic materials, Elsevier, Amsterdam.

[2] JEDRZEJEWSKI J., GRZESIK W., KWASNY W., MODRZYCKI W., 2008, Process - machine tool thermal interaction, Journal of Machine Engineering, 8/3, 91-106.

[3] ARRAZOLA P.J., OZEL T., UMBRELLO D., DAVIES M., JAWAHIR J.S., 2013, Recent advances in modelling of metal machining processes, CIRP Annals-Manufacturing Technology, 62/2, 695-718.

[4] MELKOTE S., GRZESIK W., OUTEIRO J., RECH J., SCHULZE V., ATTIA H., et al., 2017, Advances in material and friction data for modelling of metal machining, CIRP Annals-Manufacturing Technology, 66/2, 731-754. 
[5] ZEMZEMI F., RECH J., BEN SALEM W., DOGUI A., KAPSA PH., 2009, Identification of a friction model at tool/chip/workpiece interfaces in dry machining of AIS14142 treated steels, Journal of Materials Processing Technology, 209/8, 3978-3990.

[6] RECH J., ARRAZOLA P.J., CLAUDIN C., COURBON C., PUSAVEC F., KOPAC J., 2013, Characterisation of friction and heat partition coefficients at the tool-workmaterial interface in cutting, CIRP Annals Manufacturing Technology, 62/1, 79-82.

[7] GRZESIK W., RECH J., 2019, Development of tribo-testers for metal cutting friction, Journal of Machine Engineering, 19/1, 62-70.

[8] GRZESIK W., 1998, The role of coatings in controlling the cutting process when turning with coated indexable inserts J. Materials Processing Technology, 79/1-3, 133-143.

[9] GRZESIK W., 2000, An integrated approach to evaluating the tribo-contact for coated cutting inserts, Wear, 240/1-2, 9-18.

[10] GRZESIK W., NIESŁONY P., 2004, Physics based modelling of interface temperatures in machining with multilayer coated tools at moderate speeds, Int. J. Machine Tools and Manufacture, 44/9, 889-901.

[11] GRZESIK W., NIESŁONY P., 2003, A computational approach to evaluate temperature and heat partition in machining with multilayer coated tools, Int. J. Machine Tools and Manufacture, 43/13, 1311-1317.

[12] AKBAR F., MATIVENGA P.T., SHEIKH M.A., 2010, Prediction of heat partition in metal cutting - a state-ofthe-art review of conventional and high-speed machining, Chapter 2 in ed. J.P. Davim, Metal Cutting, Research Advances, Nova, New York.

[13] GRZESIK W., NIESŁONY P., LASKOWSKI P., 2017, Determination of material constitutive laws for Inconel 718 superalloy under different strain rates and working temperatures, J. Materials Engineering and Performance, 26/12, 5705-5714.

[14] GRZESIK W., BARTOSZUK M., NIESŁONY P., 2005, Finite element modelling of temperature distribution in the cutting zone in turning processes with differently coated tools, J. Materials Processing Technology, 164-165, 1204-1211.

[15] GRZESIK W., BARTOSZUK M., NIESŁONY P., 2004, Finite difference analysis of the thermal behavior of coated tools in orthogonal cutting of steels, Int. J. Machine Tools and Manufacture, 44/14, 1451-1462.

[16] GRZESIK W., 2006, Determination of temperature distribution in the cutting zone using hybrid analytical-FEM technique, Int. J. Machine Tools and Manufacture, 46/6, 651-658.

[17] GRZESIK W., NIESŁONY P., BARTOSZUK M., 2005, Comparative assessment of the tool temperature prediction using analytical and simulation methods, Proc. $8^{\text {th }}$ CIRP International Workshop on Modeling of Machining Operations, May 11-12, Chemnitz, Germany, 659-666.

[18] GRZESIK W., 2005, Analytical models based on composite layer for computation of tool-chip interface temperatures in machining steels with multilayer coated cutting tools, Annals of the CIRP, 54/1, 91-96.

[19] GRZESIK W., 2001, An investigation of the thermal effects in orthogonal cutting associated with multilayer coatings, Annals of the CIRP, 50/1, 53-57.

[20] GRZESIK W., 2006, Composite layer-based analytical models for tool-chip interface temperatures in machining medium carbon steels with multi-layer coated cutting tools, J. Materials Processing Technology, 176/1-3, 102-110.

[21] NIESŁONY P., GRZESIK W., LASKOWSKI P., ŻAK K., 2015, Numerical 3D simulation and experimental analysis of tribological aspects in turning Inconel 718 alloy, Journal of Machine Engineering, 15/1, 47-57.

[22] GRZESIK W., RECH J., ŻAK K., 2014, Determination of friction in metal cutting with tool wear and flank face effects, Wear, 317/1-2, 8-16. 